\title{
Investigating the Place of Imagination in Farabi's Epistemological Theory
}

\author{
Suhayb Amin Nadir (Hawzhin Mala Amin) ${ }^{1}$ \\ ${ }^{1}$ Department of Sociology, University of Sulaimani, Iraq \\ Correspondence: Suhayb Amin Nadir, Department of Sociology, University of Sulaimani, Iraq. E-mail: \\ suhyab.amini52@gmail.com
}

Received: June 27, 2015 Accepted: July 1, 2015 Online Published: August 18, 2015

doi:10.5539/ass.v11n22p220

URL: http://dx.doi.org/10.5539/ass.v11n22p220

\begin{abstract}
The issue of the role of imagination and its importance and position in Islamic epistemological structure, especially for Farabi and advocates of Gnostic approach, has established the chance to achieve a theoretical framework in understanding Islamic epistemology. For Gnostic approach advocates, wisdom and truth have appearance, essence, perception, and intuition in a way that imagination as a means of abstraction of objects and shapes from their material reality has an active and decisive role in creation of wisdom and truth, it can also interpret human conscience and inner being; therefore, as a theoretical means for thought and analysis, the basis for imaginative reaction is to symbolize and interpret. From this perspective, every sensory experience and awareness necessarily contains a certain level of imaginative nature and quality.

There is a special type of dualism in Farabi's approach and imagination which is related to his interpretation of religion and religious reality. He believes that religious truth is a metaphorical, artistic, literary, and imaginative truth. For him, human possess another unique value which is the value he generally possesses towards art and aesthetic work. Another important point according to Farabi is the difference between philosophy and religion. According to him, philosophy inclines towards sense and experience while religion deals with intuition, predictions, and speculation. In intuition, philosophy supports necessity whereas philosophy supports essence, and this is what causes to think that these two are of different types. Due to their differences, specific transverses have appeared in them. This division cannot be solved except for Farabi's philosophy and his epistemology theory which is based on the unity between nature and essence (from the beginning) and totally deals with maintenance of balance.

Farabi's epistemology theory in imagination is a philosophical-rational theory that is based on logical credits and rational preliminaries and bold dependence on the relevant results. From this perspective, Farabi was creative in philosophical speech and has exceeded the words of Plato and Aristotle, and through imagination his theories proposed a new critical epistemology in associations like religion and philosophy, art and science, and wisdom and essence, which was effective in the history of philosophy after him.
\end{abstract}

Keywords: imaginativism, epistemology, ontology, active intellect, existence, necessity

\section{Introduction and Background}

Islamic scholars have seldom paid attention to imagination and its position in the system of Islamic epistemology. Position of imagination in Islamic philosophy and especially in Islamic epistemology and specifically for Aristotle and the strong position of rational reason, imagination is an issue that scientific communities of Islamic countries have never paid attention to. Henry Carbon, Nasrullah Hekmat, William Chitik, Maryam Sane'pour, Rashideh Kalla', and Hazim al-Ghartanji are among scholars who have paid limited attention to the role of imagination in mystics, rhetoric, and Islamic critic. An important point in these studies is the relationship between imagination and theoretical mysticism and illuminative approach and transcendental philosophy and the relationship between Sahrvardi and Ibn Arabi and Sadr al-Din Shirazi.

The present mainly study deals with Farabi's effect on Islamic philosophers' approach and Islamic epistemology. Farabi's epistemology in imagination is a philosophical-rational theory and relies on rational credits, logical preliminaries, and bold submission to its relevant results. In fact, the position of logic for him and his position in logic are noteworthy. Another important point is that Farabi did not consider logic as a mere entry; however, he 
thought of it as a basis for philosophical speech in metaphysical framework. In this regard, he is like the American philosopher Josiah Royce who preceded him centuries. Royce (1855-1916) is neo-Hegelian and tried to unite idealism and pragmatism and philosophy and religion. He considered logic as a necessary means to achieve this significant goal (Royce, 2009, p. 215).

Investigation into this issue and the approach of queries adopts mechanisms of analysis and interpretation, and through them and from the perspective of epistemology it tries to examine Farabi's philosophical and epistemology in a framework in order to reveal the importance of imagination in Farabi's epistemology and his role in creation of the new concept of epistemology (imaginative epistemology). The present study was conducted in order to explore this theory in the structures of epistemology and ontology which have a metaphysically tight relationship.

\section{Ultimate Division as Unity}

In regard with the issue of essence and existence in Farabi's definition, there are some questions such as whether he believes that essence and origin have priority over existence or vice versa? Some believe that Farabi is the first philosopher that paid attention to this issue and tried to solve it. Sadraldin Shirazi later stated this issue first in regard with the contradiction and second tendency toward existentialism (Khayyereh, 2013, p. 48). Now, the question is that whether Farabi believes in existentialism or essentialism (al-Farabi, 1988, p. 74) or believes in something other than these two.

Farabi is the first one that has considered the theory of unity of existence and essence self-existent. However, stating for the first one that there is no essence other than existential essence is the same as claiming that existence is truth if it possesses the necessary quality which is existentialism (al-Farabi, 1988, p. 42).

This short statement refers to the point that essence is existence and there is no essence other than existence; therefore, the two are the same. Therefore, the first creature is the same essence (self) of existence. And since the real existence for every creature is not anything other than the specific existence that is outside the soul, all real creatures are in fact a grant from Him and a sign for His presence; therefore, their existence is from Him, which is and existence for the way of imagination because it is actually nothing outside His soul. So whatever is originated from self-existence is merely because of their belonging to Him, and the rational images are originated from His existence (al-Farabi, 1988, p. 44). This self-existence is reason, rational, and reasonable, and only His existence (He Himself) thinks because there is nothing but Him such that there is no creating existence other than reasonability for His own essence (al-Farabi, 1988, p. 45).

Therefore, the belief that one of them is prior to the other one is not compatible with Farabi's philosophy that is mainly based on unity between the two, and what is important is the essence of imagination.

According to Farabi, thought in response to "What is this?" is called essence since it is reasonable, and in regard with its existence outside, it is called reality (Jahami, 1998, pp. 862-863). Correctness of this reality depends on the compatibility and creative power of imagination and negation of realization barriers, among which one can brefer to contradiction between imaginations and contradiction of imagination companying with movement (al-Farabi, 1988, pp. 57-58).

The fundamental problem that Farabi highlights clearly out of the statement, existence unity and essence in necessity, is that this issue can hardly be abstracted because His reasonability is the same necessity and essence.

According to Farabi, what is noteworthy is that active intellect gets involved with creation by affecting the initial or the common material and gives images to this material, and by imposing and assuming reasons for it, the intellect domination over them will be possible. However, the second ones have the same appearance or due to their relative simplicity, they are all given one appearance. An instance is celestial bodies whose common essence or quality is their initial common material for all creatures existing in the universe (al-Badavi, 2006, p. 106, Vol. 2).

The appearance of Farabi's statement indicates that celestial intellects, souls, and active intellect do not turn into imagination neither into sense; however, they inspire it. Although imagination and thinking are different, they are one thing; however, they are different from one intellect to another and from one soul to another. Therefore, where there is imagination, there exists creation, and this imagination is unique to intellect which is interpreted as blessing and is merely an abstraction from internal senses of cognitive activity. Farabi states, "The stars are imagined in the form of slight movement, and movement does not reach them, and these bodies are bound to movement. So you think of what is created out of this movement and understand it, and you do not understand what is created other than the movement. And if one could imagine other than the movement, it would be necessary that two movements be created; however, it is impossible and those bodies do not imagine 
impossibility although it is not fake.

On the other hand, Farabi has founded a thought that intuition or sensory observation is reflection or intuition, and imagination intellect is the abode for and surrounds both and is like the initial or abstracted material. Farabi has really affected these two a lot and there is no doubt that he mastered over them and took different ways through them because environment is a container for them. In fact, this activity is close to Farabi's understanding of gender tie as male and female. Female is the same female or a power that material provides and male is the same male or material that gives it an appearance that provides the power (Farabi, 1986, p. 97).

In the $19^{\text {th }}$ chapter of his book, "Views of utopia residents", Farabi focuses on sequence of images on the main material. He states that existence is in fact a total unity and soul, powers and talents are a stage of existence, the most inferior of the lowest material for the highest level, and the highest or most valuable for the most inferior. Aristotle's statements and approaches have sometimes affected Muslims. Therefore, he is the first one that has stated, "Soul is the initial completion of the body with living powers (Badavi, 1980, p. 30), whereby he has joined the soul with the body firmly, and if it is separated from soul, the body will not exist. Therefore, if we imagine a gradual ladder for creatures, all of them are created from the main material and appearance.

\section{On Soul and Intellect}

The second or average level, understanding and awareness, is the firmest and most reasonable one. The researcher tries to name this level best which is speech on imagination, orders, and secrets, and belongs to all troublesome philosophical issues that Farabi encountered with and attempted to solve and imagined the essence of his philosophy and is based on his imaginative logic. Therefore, despite of many similar aspects, his logic is Aristotelian imaginative and not Platonic dialectic one, and in fact, it is a new type of both. In this regard, Farabi is completely like Hegel. His uniting philosophy does not bring about unity, to an extent that the solver and the creation activity are new, phenomenology is specific, in which all philosophical and religious heritages affect one another. His philosophy is not the collection of these to philosophers, neither the unity between religion and philosophy or philosophy and literature and art and music and immateriality of mathematics, but it is gnostic, in which divine is tied to human, intellectual to material, social to individual, subjective to objective, and imaginary to reality. In his philosophy, Gnosticism is tied with a type of trust, reasonable with unreasonable, real empirical materialism with idealism, and mysticism with intuition and traditionalism, in a way that it later included all structures and studies especially schools of Islamic and human thought. In his philosophy, his personal surrounding and understanding of myths form, and there are studies on his methods, resources, and cognition in oral speech. This philosopher has considered it as an acquired reality like human as an incomplete form. Farabi is named "the second teacher" because of his superiority in logic and rank of knowledge writings (Nasr, 2003, p. 431). Due to his superiority in writing issues and their relationship, existence and creature and their ranks, his ponder in meaning of words and the boundary of objects and group relationship of them with each other, and the properties of studies, and types of speech, serious issues are brought forth in this type of research in the field of science philosophy and epistemology. All of these levels of research have a direct relationship with logic in accordance with Farabi's concept of these sciences which are bound to obtaining prosperity and goodwill.

The present study focuses on reason and imagination or soul and power in order not to digress from the issue and deal with different schools and ways. Therefore, these are the main issues that the present study deals with. Muslims have been affected by the definitions and approaches about soul proposed Greeks, especially Aristotle and Plato. For these two philosophers, the issue of soul has a close relationship with wisdom. Plato's theory about reminder is clear, and some scholars believe that in Aristotelian religion, there is a close relationship between soul and rejection of this theory by him and the world of forms. He understood the origin of the theory of forms by Plato. Therefore, he decided not to accept the foundation on which Plato's theory was based, which is presented $i$ the theory of immaterial or spirituality of the soul (Ghasem, 2002, pp. 70-71).

The present study is aimed at resolving the severe ambiguity in how some Muslims deal with these two philosophers, which has caused religious sensitivity and confusion of temporary Islamic philosophers and jurists (Badavi, 1980, p. 12). This confusion causes misunderstanding their ideas such that Farabi is accused of making contradicting comments about soul and intellect, and that he is doubtful about Aristotle and Plato and has made many strange comments (Ghasem, 2002, pp. 74-75).

Farabi states, "Soul is the first perfection for the body and possesses power and life" (Ghasem, 2002, p. 73). Soul is the created form within the body and completely belongs to it and to the material of the initial material (Ghasem, 2002, p. 75). Therefore, soul is a necessity for individuals while it disappears as the body dies. The initial gems that individuals hold inside their bodies do not need anything except for soul; however, secondary gems include all generalities that individuals need inside themselves. Therefore, individuals have priority over 
the so-called general gems (al-Farabi, 1987, p. 89). However, generalities are constant. Moreover, abstract intellectual concepts after destruction of individuals and bodies, generalities will sustain; therefore, generalities under the label of individual gems have priority (Farabi, 1987, p. 89) because reasonability in the same abstract existence of that thing (Farabi, 1988, p. 46).

About human and intellect, Farabi states, "It is true that a child has a soul that is aware of its power and has senses that are tools to understanding details out of generalities which in turn are experiences, and when soul forms out of these experiences, the soul becomes wise because wisdom is not other than experiences, and with more experiences, the soul will becomes wiser (Farabi, 1986, p. 98). Therefore, what actualizes the child's world wisdom and soul is specifically the same works accomplished by cognitive tools that are senses and experiences. Therefore, reason has no appearance and cannot be defined or specified and does not have nature; however, it turns into forms. Therefore, reason does not naturally have any form, but if a form appears, there will be a barrier between it and external forms (Badavi, 1980, p. 20). Farabi also emphasizes that for reason and soul to be acquirable is not anything other than experiences. Is there any other activity that meddles in this activity? Does anything else other than experiences interfere with mental and intellectual growth of a child? Farabi believes that there are two types of experiences; those obtained on purpose and those acquired without any intention. Scholars name experiences obtained without intention the preliminary knowledge, reason basis, and things like that, which are kinds of knowledge that most people doubt about they have always existed in the soul (Farabi, 1986, p. 99). So when these aimless experiences are acquired, most people are confused and doubt that they have always existed inside the soul and are the beginning of knowledge and basis for reason. The soul becomes wise through action because wisdom is not other than experiences (Farabi, 1986, p. 99). So what make wisdom become actualized is merely the experiences that are acquired without any intentions, and most people think that they have always existed in the soul; therefore, the thought that there are initial knowledge or forms or concepts or principles before experiences is not more than a delusion.

Under another topic, Farabi talks about active intellect which causes forms and negates and orders things that exists in the universe, a wisdom that is originated from the forms of creatures, including solids, plants, and animals, or from human soul. He is fame for his theory about the mediation between active intellect and its relationship with prophet and philosopher does not need to be mentioned.

Although the first hypothesis is in line with the form of some statements by Farabi, especially those made in "Fosus al-Hikam" and with the appearance of religious thought; however, it is in contradiction with Farabi's logic and thinking system which puts emphasis on a kind of phenomenalism and believes that human does not know the reality of the object because his basis for his knowledge is his sense, then he distinguishes between similarities and dissimilarities with his reason, whereby he knows some of his equipment, internalities, and qualities through which he gradually approaches a limited knowledge about his achievements (Jahami, 1998, p. 124).

\section{On Transcendental Intellects}

The concept of transcendental realities is the fundamental problem and challenge that sometimes Farabi is faced with. Islamic philosophers know these realities as intellects each of which is active compared to its subordinate and inactive compared to its superior. An example is the active intellect dominating the things that exists in the universe, and this is the same challenge that interprets what Farabi states about human soul or intellect. In this regard, Eskandar Afroudisi, the first interpreter of Aristotle, believes that active determining intellect that Aristotle talks about its sustainability is holy and pure God. However, Ibn Roshd, his greatest interpreter, believes in eternality of human soul and what Aristotle believed about intellect is because of this eternality, he also believes that active intellect is the only essence of human soul (Badavi, 1980, pp. 5-10).

However, based on his theory of blessing, Farabi believes that the foundation of existence and the comprehensive essential reality in which existence and essence unite is reason. This theory or interpretation that brings the universe and corruption under its 10 disciplines and systems according to a numerical system, and this is the interpretation that has more agreement with Farabi's logic and his thinking system. Therefore, intellect or reason, existence on metaphysical level is the same rules or initial categories and necessary eternal principles in which corruption and change cannot occur; therefore, these are its origin, and human does not achieve them intentionally, but he obtains them through unintentional experience along with sensory understanding. And, here Farabi interprets them as unintentional or urgent experiences.

Farabi's attempts in this regard caused the two philosophers and philosophy and religion to unite, and his pondering on reason caused a third theory to be created, in which there is a kind of similarity and closeness between Farabi's concept of form and Hegel's temper and synthesis. For Farabi, form is basically derived from 
the relationship and dialect between the two; necessity and refusal, existence and absence. In the reason, there is no special reaction to sense except for understanding of all objects and opposition and imagination of creatures (Farabi, 1986, p. 99). Moreover, Farabi believes that sense understands an object; the external form of the object; however, the reason understands what sense perceives and its opposite (Farabi, 1986, p. 99).

This dialectic essence accompanies awareness and imagination of an object and its opposite, which is both a reaction and a fantasy and imagination. It prepares the situation for thinking and reasoning. However, what makes this activity certain is confirmation of rejection of the form, which is the first principle of existence and is called the perceived necessity through intuition and sensory experience, which cannot be separated from existence. The same present existence principle in this creature and with its existence will gain the credit to pass for its abstracted form and will be sensible after it has separated, which is accomplished with active intellect, i.e. the imagination that causes this form. In this conditions, the form will be abstracted from its imaginary world, and all imagination and abstractions and in fact the reason will be the same principle for prediction of abstract motivators.

Farabi is the first believer in the theory of existence unity in the system of Islamic thinking. After him, no Muslim philosopher or mystic, in spite of their intellectual features, have not freed from this theory. This religion is in the unity of intellectual schools and the conclusion is that intellect is the origin. Therefore, the principles of transcendent single abstraction and then the abstraction principle or the principle of systematic abstraction is based on imagination and whatever is reasonable, to the highest level, is imaginary, on which revealed imagination has influenced, which means the structure of existence on the level of awareness is an imaginary one and it is impossible to neglect imagination in the presence of the reasonable.

\section{Human and His Understanding Structure from Farabi's Perspective}

Human is one of the creatures whose perfection was not bestowed to him from the beginning. He is one of the creatures that have given the most deficient perfection. Meanwhile, he has given some principles whereby he tries and progresses in order to reach perfection through instinct and nature or on his own intention (Jahami, 1998, p. 124).

With these definitions, human is a combination of instinct and intention and he specifically approaches perfection, and he uses the principle to reach perfection (Ibid, 124). In this regard, there are two types of wisdom; the first type and the created necessary rules for him without intention and along with tendency toward generalization, and this is what can be emphasized in tastes an cannot be separated from it. In knowledge and intention and beliefs and legal and Sharia rules and civic interactions, the emphasis is on the whole time of induction of details like the principle that any stone sinks in the water and some may float (Farabi, 1986, p. 82). Therefore, any intention of understanding objects a human bears in mind is caused by awareness of the situations and strictness of that situation, and this is only the demand of the object that exists inside his soul (Farabi, 1986, p. 99). It seems that he seeks a kind of agreement with his soul within the unity between what exists inside him and what he finds outside and by combining the condition he possesses and what is there in his soul, which means the cognition activity is the activity of compromising with soul within compromising with reality. This is a kind of activity is generalization, comparison, analogy, and a kind of real remembrance; however, it is different from Platonic ideal remembrance because observation and experience are the basis for knowledge. Therefore, the apparent five senses and their perception belong to the power of senses, which is the same place where intellect and material meet and sense is only choosing the existing form, and this is the simplest level of understanding which forms a type of understanding or sense, through which human understands, sees, hears, and touches himself and this is a type of internal perception.

According to Farabi, when human was created, the first thing that forms inside him is his sensory part along which there is a tendency toward something that he feels, then another power maintains the opposite of the felt things, which is called imagination power that combines sensible things together and separates from one another. It accompanies with different combinations and separations, truth and fakeness; however, it keeps a tendency toward things he imagines (Farabi, 1986, p. 87). And there is a distinction between sensible things for the common sense, like distinction between white and black in visionary understanding. Therefore, the distinction power is used for different senses and coordination among them by use of law of association, and also understanding the form, continuum, place, amount, motion, volume, and distance play an important role in evolution of sensory knowledge and acquisition of experiences in order to understand common sensible things. Afterwards, the role of imagination will be put forth, and imagination power catches the effect of common sense and welcomes it, and after it hides, imagination will understand it, and sometimes it is an invention in agreement or disagreement with the truth, and in this case imagination power is submissive to intention and willing, and 
sometimes it occurs without intention as happens in sleep and daydreams. Afterwards, the memory (reminder) comes, which is based on imagination power. And after it, illusion and intuition power will come, which understands incomprehensible concepts in detailed sensible things, like sheep's understanding of wolf. Illusion power understands through inspirations, opacity, and symmetries and distinguishes benefits and losses and acts like a judge because it is the origin of principles and beliefs that reason trust in their correctness and certainty, like belief in the fact that every confused creature in in a place; therefore, this power is the origin of intellectual principles. Afterwards, memory comes, which stores whatever illusion understands (al-Kordi, 2003, pp. 57-112).

In Farabi's perspective, active intellect which is the same extra category of intellectual form, as Gabriel is the religious form for Him and this is the same category that orders and influences on the world of human understanding through these categories. In other words, active intellect is the same fundamental form that collects all categories, and this intellect is one of them. However, the speaking power, which is like active intellect and on the same level, is an imagination that alters between sensible issues and the principles, and it seems that active intellect is divine imagination and speaking power is human imagination.

The theory of blessing goes into the details of this fact and lightens an interpretation on the level of understanding and awareness. So he ponders on his essence, specifies and defines and delimits it and surrounds it completely, i.e. he imagines and depicts it as if he separates necessity from existence, and this is a kind of internal feeling, awareness of the soul, which is established in the whole essence, then it becomes full which cannot be controlled on the level of human imagination because $\mathrm{He}$ is the greatest entity and has the complete form and its necessity is consideration and heed. What does the intellect do? He imagines His essence within His essence, i.e. He imagines and understands His essences as a form or imagination, or through this another depiction for His abstracted reality will be issued, so a form with more visibility will be created. Therefore, trend and orientation of this thinking is blessing and He thinks of His essence, and this thinking is returnable and reversible; therefore, secondary reason and mental tendency and motion will be issued. The first thinking does more like the internal understand "I think" and He is the necessary condition for understanding the external reality and truth. These three are the essence of the theory of blessing on the level of single or reasonable creature or the simple cognitive unity whether it is imagination or affirmation, and it depicts awareness nature and understanding and structure of the form or thinking in an apparent expression. Therefore, human logic for awareness is necessarily apparent and imaginary. Thus, if thinking of the soul were not the beginning and if its role were not like the role of light in the body, it would be necessary to interpret it as revelation and blessing.

The issue for Farabi is not existence and essence because they are the most obvious and at the same time the most hidden issues. However, the problem is with the structure of awareness and human perception and the mediation of imagination in every perception and thinking because sometimes it is believed that the appearance of objects is obtained in the reason, the time for straightness of sensible entities without mediation; however, the issue is not like this and there are actually mediators among them and the reason is the form of all these mediators. Therefore, sense directly deals with sensible things and the forms of the sensible things and results in mutual sense. Thus, its common sense brings the forms to imagination and imagination to distinction power, so it can performs with purity within it and brings it to reason and guess in a purified way (Farabi, 1987, p. 104). Therefore, the basis for knowledge is sense unless the reasonable belongs to an abstract object (Jahami, 1998, p. 814). And imagination is carried out with reason, and human feels issues that are outside the soul and their forms are obtained in the senses combined with relationships. And the imaginer performs in a very abstracted way and imagines and feels his soul within it in a way that the one who is outside is the same sensible issue which is not in fact in agreement with the thing that exists in his soul such that he understands the difference between two forms, which is the peak of abstraction. Therefore, the reason is the most delicate thing and what it imagines is the most delicate imagination (Farabi, 1987, p. 103). Therefore, although the initial sense is reason that is not anything other than experiences and since all understandings and thinking are combined with imagination unless the sensible issue is clear rather the high samples are for knowledge (Farabi, 1987, p. 105).

According to Farabi, the right thing that imagination creates is selecting and extracting in the mind, which is the thing that gives experiences meaning. Therefore, when the imagination power succeeds in understanding these issues or reasons, miracle will occur and this essence will be expressed among other powers of the soul, and "if fantasy utilizes it, it is called imagination" (Farabi, 1979, p. 79), and in its holy complete level, it is the inspiring source for forms, samples, ideals, and imaginations in a way that an inspiring source in theory, reason, and selection in theoretical and practical philosophy will be created. In a general form, it is concluded from philosophy and the Prophet that philosophy inspires abstraction and likewise the Prophet inspires analogy, imagination, and symbol. The philosopher inspires high imagination or the performance of the reason within the sensible and ideal samples and forms with their abstraction while the Prophet inspires future imaginations, 
approaches, and symbols and their forms, whereby he imagines unity of religion and reason and that of art and science, and prepares theories for the community and provides the opportunity for human's perfection and real prosperity, which in turn creates the real balance inside the human who is equipped with the two wings of reasonable and unreasonable or imaginary ones. This power is talents and readiness that intensifies among some people until there is no need for that big thing. Its perfection is depicted by philosopher, prophet, or scholar poet, someone who deserves being called human because it is not impossible that human's imagination power reaches its ultimate perfection and is affected by active intellect and reasonable and transcendent imitations are accepted, through which human has a responsibility toward divine things and this is the complete level of imagination power (Farabi, 1986, p. 115).

\section{Conclusion}

Discussing the role and importance of imagination in the structure of epistemology creates new horizons in a way that our ideas about Islamic philosophical and in short the gnostic scholars in Islamic philosophy are influenced by the second teacher. In this regard, knowledge and reality have appearance, inside, understanding, and intuition, and imagination plays an active and decisive role in its structure, and any awareness and sense necessarily has a certain amount of imagination.

There is a special type of dualism in Farabi's approach and imagination which is related to his interpretation of religion and religious reality. He believes that religious truth is a metaphorical, artistic, literary, and imaginative truth. For him, human possess another unique value which is the value he generally possesses towards art and aesthetic work. Another important point according to Farabi is the difference between philosophy and religion. According to him, philosophy inclines towards sense and experience while religion deals with intuition, predictions, and speculation. In intuition, philosophy supports necessity whereas philosophy supports essence, and this is what causes to think that these two are of different types. Therefore, a type of symbolism and affection and brevity ad interest accompanying with the form dominates him. And finally, it takes the extremist form of formalism, in a way that sometimes philosophy becomes an extremist form of idealism. This derivation and division cannot be solved except for through Farabi's philosophy which is based on unity of existentialism (from the beginning) and ultimately deals with maintenance of the balance and places the world of awareness as the world of darkness and is based on essence and its principles are among the appearance, the inside part, the reason, and the form.

Shortly, the present study was aimed at highlighting the fact that Farabi has caused innovation in speech and has exceeded from Aristotle and Plato's words, and his ideas are a combination of religion and philosophy, art and science, and reason and existence. He established a critical epistemology that has a remarkable effect on the whole history of philosophy, and this effect is apparent in the tradition of Islamic and Western philosophy.

\section{References}

al-Farabi. (1979). Stages of rules (1st ed.). Research: Muhammad Hasan Al Yasin: Ma'arif Publication: Bagdad. Islamic Publication and Service Center.

al-Farabi. (1986a). The collection of the remarks of scholars (2nd ed.). For and against steps toward Albert Nasri Nader, Dar al-Mashriq, Kasulikiyah Publication.

al-Farabi. (1986b). The views of the residents of the Utopi: For and against (2nd ed.). Dar al-Mashriq Publication: Beirut.

al-Farabi. (1987). Philosophical letters (The responses to questions) (1st ed.). Jafar Al Yasin. Dar al-Manahil Publication: Beirut.

al-Farabi. (1988). Reviews (1st ed.). Research by Jafar Al Yasin, Dar al-Manahil: Beirut.

al-Farabi. (1990). The Book of Unity (1st ed.). For and against views about Mohsen Mahdi. Dar Tubghal Publication: Al-Morocco.

al-Farabi. (n. d.). The policy of city. Electronic Library of al-Mustafa. Retrieved from http://www.al-mostafa.com

Badavi, A. R. (1980). Aristotle in soul (2nd ed.). Wikalat Press: Beirut, Kuwait, Dar al-Ghalam.

Badavi, A. R. (2006). Encyclopedia of philosophy (1st ed.). Zuwi al-Ghuraba Publictaion: Ghom.

Descartes, R. (2008). Hadith al-tarighat (1st ed.). Arabic Translation Center.

Ghasem, M. (2002). Within the soul and reason of Greek and Islamic philosophers (3rd ed.). Makhmirat Publication: Maktaba al-Anjilo al-Misriya.

Jahami, J. (1998). Terminology of philosophy for Arabs (1st ed.). Nasherun Publication: Beirut. 
Kheyyereh, H. B. (2013). Essence and existence according to Farabi. Bin Bu Ali University. The Academic Journal of Humanities and Social Sciences, Philosophy Section, 10.

Royce, J. (2009). Fundamentals of logic (2nd ed.). The center of local translation.

\section{Copyrights}

Copyright for this article is retained by the author(s), with first publication rights granted to the journal.

This is an open-access article distributed under the terms and conditions of the Creative Commons Attribution license (http://creativecommons.org/licenses/by/3.0/). 